\title{
Defecation frequency and timing, and stool form in the general population: a prospective study
}

\author{
K W Heaton, J Radvan, H Cripps, R A Mountford, F E M Braddon, A O Hughes
}

\begin{abstract}
Because the range of bowel habits and stool types in the community is unknown we questioned 838 men and 1059 women, comprising $72 \cdot 2 \%$ of a random stratified sample of the East Bristol population. Most of them kept records of three consecutive defecations, including stool form on a validated six point scale ranging from hard, round lumps to mushy. Questionnaire responses agreed moderately well with recorded data. Although the most common bowel habit was once daily this was a minority practice in both sexes; a regular 24 hour cycle was apparent in only $40 \%$ of men and $33 \%$ of women. Another $7 \%$ of men and $4 \%$ of women seemed to have a regular twice or thrice daily bowel habit. Thus most people had irregular bowels. A third of women defecated loss often than daily and $1 \%$ once a week or less. Stools at the constipated end of the scale were passed more often by women than men. In women of child bearing age bowel habit and the spectrum of stool types were shifted towards constipation and irregularity compared with older women and three cases of severe slow transit constipation were discovered in young women. Otherwise age had little effect on bowel habit or stool type. Normal stool types, defined as those least likely to evoke symptoms, accounted for only $56 \%$ of all stools in women and $61 \%$ in men. Most defecations occurred in the early morning and earlier in men than in women. We conclude that conventionally normal bowel function is enjoyed by less than half the population and that, in this aspect of human physiology, younger women are especially disadvantaged.
\end{abstract}

Of all human bodily functions defecation is perhaps the least understood and least studied. Limited data have been published on the bowel habits of postmen, ${ }^{1}$ nurses, ${ }^{2}$ students, ${ }^{3}$ old people, ${ }^{4}$ and men in prison. ${ }^{5}$ No data are available, however, for the general adult population except for one study in the USA which relied simply on a door step interviewer asking 'How often do you usually have a bowel movement?'. 6 The widely quoted statement that $99 \%$ of normal

TABLE I Age and sex of the subjects studied $(72 \cdot 2 \%$ of $a$ stratified random sample of the East Bristol population)

\begin{tabular}{lccccccc}
\hline & \multicolumn{6}{c}{ Number of subjects in each age group (years) } \\
\cline { 2 - 7 } & $25-29$ & $30-39$ & $40-49$ & $50-59$ & $60-69$ & All ages \\
\hline Men & - & - & 430 & 226 & 182 & 838 \\
Women & 305 & 328 & 199 & 142 & 84 & $1059 \star$ \\
\hline
\end{tabular}

^The age of one woman was unknown. people defecate between three times per week and three times per day derives from a survey (carried out 30 years ago) of workers in a food factory and patients attending their general practitioners for non-gastrointestinal complaints. ${ }^{7}$ All reported studies have assumed that people's statements about their bowel habit are accurate. People tend to exaggerate, however, and one in six misreport their bowel frequency by three or more stools per week. ${ }^{89}$ Clearly there is a need for prospectively recorded data.

Frequency of defecation is easy to assess but is a poor guide to colonic function, bearing little or no relation to intestinal transit time or daily faecal weight..$^{9-12}$ In contrast, stool form and stool consistency are well correlated with transit time and faecal output. ${ }^{11}{ }^{12}$ It is not feasible to measure stool consistency in a field study but it seems that untrained people can assess the form of their stools with reasonable accuracy. Self-assessed stool form on a seven point scale was well correlated with intestinal transit time in a study of outpatients with irritable bowel syndrome ${ }^{12}$ and in young women it was well correlated with symptoms of straining and urgency. ${ }^{13}$ There are no reports of stool form in the community. Such information would help clinicians evaluate their patients' complaints of diarrhoea and constipation. If data on stool form were collected in different populations they could be used to test hypotheses that slow intestinal transit predisposes to 'western' diseases like bowel cancer, diverticular disease, gall stones and breast cancer. ${ }^{14-18}$

Data on the timing of defecation do not exist except for men in an American prison. ${ }^{5}$

To try and remedy some of these deficiencies we decided to study defecation timing and frequency and the form of the stools in a large sample of the adult British population, using written records as well as verbal reports.

\section{Methods}

\section{SUBJECTS}

This study was part of an epidemiological survey whose primary aim was to establish the prevalence of gall stones and this aim dictated the number of subjects in each sex and decade of

TABLE II The table of six stool types which was shown to each subject

\begin{tabular}{ll}
\hline Type 1 & Separate hard lumps, like nuts \\
Type 2 & Sausage shaped but lumpy \\
Type 3 & Like a sausage or snake but with cracks on its surface \\
Type 4 & Like a sausage or snake, smooth and soft \\
Type 5 & Soft blobs with clear cut edges \\
Type 6 & Fluffy pieces with ragged edges, a mushy stool \\
\hline
\end{tabular}
Canynge Hall, Bristo H Cripps

A O Hughes

Correspondence to: Dr K W Heaton, University Department of Medicine, Bristol Royal Infirmary, Accepted for publication 26 September 1991 
age. ${ }^{19}$ The 1897 volunteers who attended represented $72 \cdot 2 \%$ of a stratified random sample of all the men aged 40-69 years and women aged 25-69 years registered with 19 general practitioners in East Bristol, where practically the whole population is white and is registered with a general practitioner. Younger people were not approached because they are so mobile and hard to contact and older ones because of likely problems with eyesight, hearing, mobility and transport to clinics.

General practitioners were notified of the people in our sample who were on their lists and were asked if any were unsuitable for the survey through physical or mental incapacity. This led to three or four people being excluded. Subjects were then sent letters signed by their own general practitioner asking them to cooperate with a survey of gall stones using ultrasound scanning. A few days later a clerk telephoned the subject or, if necessary, a field worker visited their home to offer an appointment at a small local hospital. Most refusers were approached again after some months. Non-attenders were telephoned or visited again. Subjects were asked to fast for at least five hours before their appointment. The composition of the surveyed group is shown in Table I.

Between October 1987 and March 1989 subjects were given a questionnaire by one of three physician-gastroenterologists (KWH, RAM, and occasionally Dr Subrata Ghosh). This included the following questions: (1) 'Do you open your bowels every day or nearly every day?' (2) 'How many times do you usually open your bowels in a day, that is, in a 24 hour period?' (3) 'How many times in the week do you usually open your bowels?' (4) 'Do you ever look at the stool before flushing it away?' People who admitted looking at their stools were shown a list of six stool types (Table II), that is, the Bristol stool form scale ${ }^{1213}$ omitting type 7 (watery stools, no solid pieces) which we assumed to be absent in healthy people. To reduce embarrassment the doctor showing the list first said 'Obviously the stools people pass vary quite a lot but there are six types which are commonly passed; I want you to look at this list and see if it includes the type of stool you usually pass'. Then, after a suitable pause, he said 'Does this list include the type of stool you usually pass?' In practically all cases the answer was 'yes'. He then asked 'Are your stools generally of the same type or do they vary?' followed by 'What is the type number of your usual stool?'

After the interview subjects were given a printed form on which to write down after each of their next three bowel movements the date and time and the type of stool. This bowel record form reproduced the table of stool types and asked 'Were these typical bowel movements for you?' A stamped, addressed envelope was provided and failure to return the form prompted a reminder.

\section{CALCULATIONS AND STATISTICAL ANALYSES}

All bowel record forms were checked for legibility and for errors and misunderstandings. Times of defecation were transcribed into the 24 hour clock system. Data on the questionnaires and bowel record forms were entered into a computer which calculated, from the data on the forms, the time intervals preceding the second and third defecations. Results were compared for men and women and for people of different ages. They were also compared between categories of stated bowel frequency, stated stool form, recorded interdefecatory interval and recorded stool form. The significance of differences was assessed by $\chi^{2}$, analysis of variance, Kruskal-Wallis tests, Mann-Whitney tests and $t$ tests as appropriate.

To investigate a possible role of female sex hormones in determining bowel function, the assumption was made that below the age of 50 years the female subjects were premenopausal and at 50 years or older they were postmenopausal. Hence, women of 25-49 years were compared with women of 50-69 years, excluding 10 of the latter who were on hormone replacement therapy.

\section{Results}

\section{QUESTIONNAIRE DATE}

Table III shows the percentage of people claiming to defecate at different frequencies. A once daily habit was the most common in both sexes but the question about times per week showed that true once daily regularity was a minority practice, only $38 \%$ of men and $36 \%$ of women of the same age claiming seven times per week. With bowel habits other than once daily there were sex-related differences. In men a less than daily habit was much less common than a more than daily one $(14 \cdot 4 \% v 47 \cdot 8 \%$ respectively, $\mathrm{p}<0.002)$, whereas in women they were equally prevalent $(31 \cdot 6 \%$ and $32 \cdot 7 \%)$. A habit of less than three per week was claimed by far more women than men $(3.5 v 0.6 \%, \mathrm{p}<0.001)$ whereas defecating more than twice a day tended to be a

TABLE III Percentage of men and women who, in response to a questionnaire, claimed to defecate at different frequencies. The data in women are displayed in such a way as to allow comparison with men of the same age and comparison of childbearing age women with older ones. The subjects available for this analysis comprised $74.5 \%$ of the men and $70.0 \%$ of the women in the original random sample

\begin{tabular}{|c|c|c|c|c|}
\hline \multirow[b]{2}{*}{$\begin{array}{l}\text { Frequency/ } \\
\text { week }\end{array}$} & \multicolumn{2}{|c|}{ At same age (40-69 years) } & \multicolumn{2}{|c|}{ In women of 2 ages (years) } \\
\hline & $\begin{array}{l}\text { Men } \\
(n=832)\end{array}$ & $\begin{array}{l}\text { Women } \\
(n=424)\end{array}$ & $\begin{array}{l}25-49 \\
(n=832)\end{array}$ & $\begin{array}{l}50-69 \\
(n=225)\end{array}$ \\
\hline$<=1$ & $0 \cdot 2 \%$ & $0 \cdot 7 \%$ & $1 \cdot 2 \%$ & $0.4 \%$ \\
\hline 2 & $0.4 \%$ & $2 \cdot 8 \%$ & $2 \cdot 2 \%$ & $2 \cdot 7 \%$ \\
\hline 3 & $2 \cdot 6 \%$ & $5 \cdot 7 \%$ & $8 \cdot 1 \%$ & $4.9 \%$ \\
\hline 4 & $2 \cdot 0 \%$ & $5 \cdot 2 \%$ & $7 \cdot 2 \%$ & $4.0 \%$ \\
\hline 5 & $3 \cdot 7 \%$ & $7 \cdot 6 \%$ & $8 \cdot 1 \%$ & $9 \cdot 3 \%$ \\
\hline 6 & $5.4 \%$ & $9 \cdot 7 \%$ & $9.0 \%$ & $9 \cdot 3 \%$ \\
\hline 7 & $38.0 \%$ & $35.9 \%$ & $34 \cdot 6 \%$ & $36.9 \%$ \\
\hline 8 & $7 \cdot 1 \%$ & $7 \cdot 8 \%$ & $5 \cdot 4 \%$ & $8 \cdot 4 \%$ \\
\hline 9 & $7 \cdot 8 \%$ & $4.5 \%$ & $4.6 \%$ & $4 \cdot 4 \%$ \\
\hline 10 & $6 \cdot 6 \%$ & $6 \cdot 1 \%$ & $7 \cdot 2 \%$ & $5 \cdot 8 \%$ \\
\hline 11 & $1 \cdot 1 \%$ & $0 \cdot 7 \%$ & $0 \cdot 7 \%$ & $0.4 \%$ \\
\hline 12 & $4.3 \%$ & $2 \cdot 1 \%$ & $1 \cdot 3 \%$ & $3 \cdot 1 \%$ \\
\hline 13 & - & $0 \cdot 2 \%$ & - & $0.4 \%$ \\
\hline 14 & $12 \cdot 9 \%$ & $6 \cdot 1 \%$ & $6 \cdot 3 \%$ & $5 \cdot 3 \%$ \\
\hline 15 & $1 \cdot 1 \%$ & $0 \cdot 2 \%$ & $0 \cdot 4 \%$ & - \\
\hline 16 & $1.6 \%$ & $0 \cdot 7 \%$ & $0.6 \%$ & $0.9 \%$ \\
\hline 17 & $0.6 \%$ & $1 \cdot 2 \%$ & $0.4 \%$ & $1 \cdot 3 \%$ \\
\hline 18 & $1 \cdot 1 \%$ & - & $0.4 \%$ & - \\
\hline & - & - & $0 \cdot 1 \%$ & - \\
\hline 20 & $0 \cdot 7 \%$ & $0 \cdot 7 \%$ & $0.6 \%$ & $0 \cdot 4 \%$ \\
\hline 21 & $1 \cdot 2 \%$ & $1 \cdot 7 \%$ & $1 \cdot 2 \%$ & $0.9 \%$ \\
\hline$>21$ & $1 \cdot 9 \%$ & $0 \cdot 7 \%$ & $0.6 \%$ & $1 \cdot 3 \%$ \\
\hline
\end{tabular}


TABLE IV Percentage of men and women who, in response to a questionnaire, claimed each of six stool types as their usual or most common one. The data for women are shown in such a way as to allow comparison with men of the same age and comparison of childbearing age women with older ones. The subjects available for this analysis comprised $65 \cdot 3 \%$ of the men and $58.3 \%$ of the women in the original random sample

\begin{tabular}{|c|c|c|c|c|c|}
\hline \multirow[b]{3}{*}{ Stool type } & & \multicolumn{4}{|c|}{ Percentage of subjects claiming each stool type } \\
\hline & & \multicolumn{2}{|c|}{$\begin{array}{l}\text { At same age (40-69 } \\
\text { years) }\end{array}$} & \multicolumn{2}{|c|}{$\begin{array}{l}\text { In women of } 2 \text { age } \\
\text { (years) }\end{array}$} \\
\hline & & Men & Women & $25-49$ & $50-69$ \\
\hline Lumpy & 1 & $4 \cdot 3$ & $13 \cdot 0$ & $9 \cdot 5$ & $12 \cdot 8$ \\
\hline Normal & $\begin{array}{l}2 \\
3\end{array}$ & $\begin{array}{l}14 \cdot 4 \\
21 \cdot 8\end{array}$ & $\begin{array}{l}13 \cdot 5 \\
17 \cdot 3\end{array}$ & $\begin{array}{l}17 \cdot 3 \\
27 \cdot 6\end{array}$ & $\begin{array}{l}12 \cdot 3 \\
18 \cdot 2\end{array}$ \\
\hline Normal & $\begin{array}{l}3 \\
4\end{array}$ & $48 \cdot 6$ & $46 \cdot 1$ & $38 \cdot 4$ & $\begin{array}{l}18.2 \\
43.9\end{array}$ \\
\hline Loose & $\begin{array}{l}5 \\
6\end{array}$ & $\begin{array}{l}5.6 \\
5.3\end{array}$ & $\begin{array}{l}5 \cdot 8 \\
4 \cdot 3\end{array}$ & $\begin{array}{l}3 \cdot 0 \\
4 \cdot 0\end{array}$ & $\begin{array}{l}8 \cdot 0 \\
4 \cdot 8\end{array}$ \\
\hline
\end{tabular}

masculine habit $(8 \cdot 1 \%$ of men $v 5 \cdot 2 \%$ of women, $\mathrm{p}<0.01$ ). Women of child bearing age (less than 50 years) were more likely than older women to admit to defecating less than five times a week $(18.6 v 12.0 \%, \mathrm{p}<0.02)$. Otherwise, there was no consistent relationship between age and claimed bowel frequency.

Most people admitted that they sometimes inspected their stools, men slightly more so than women $(92.8 \% v 89 \cdot 2 \%, \mathrm{p}<0.01)$. Routine stool
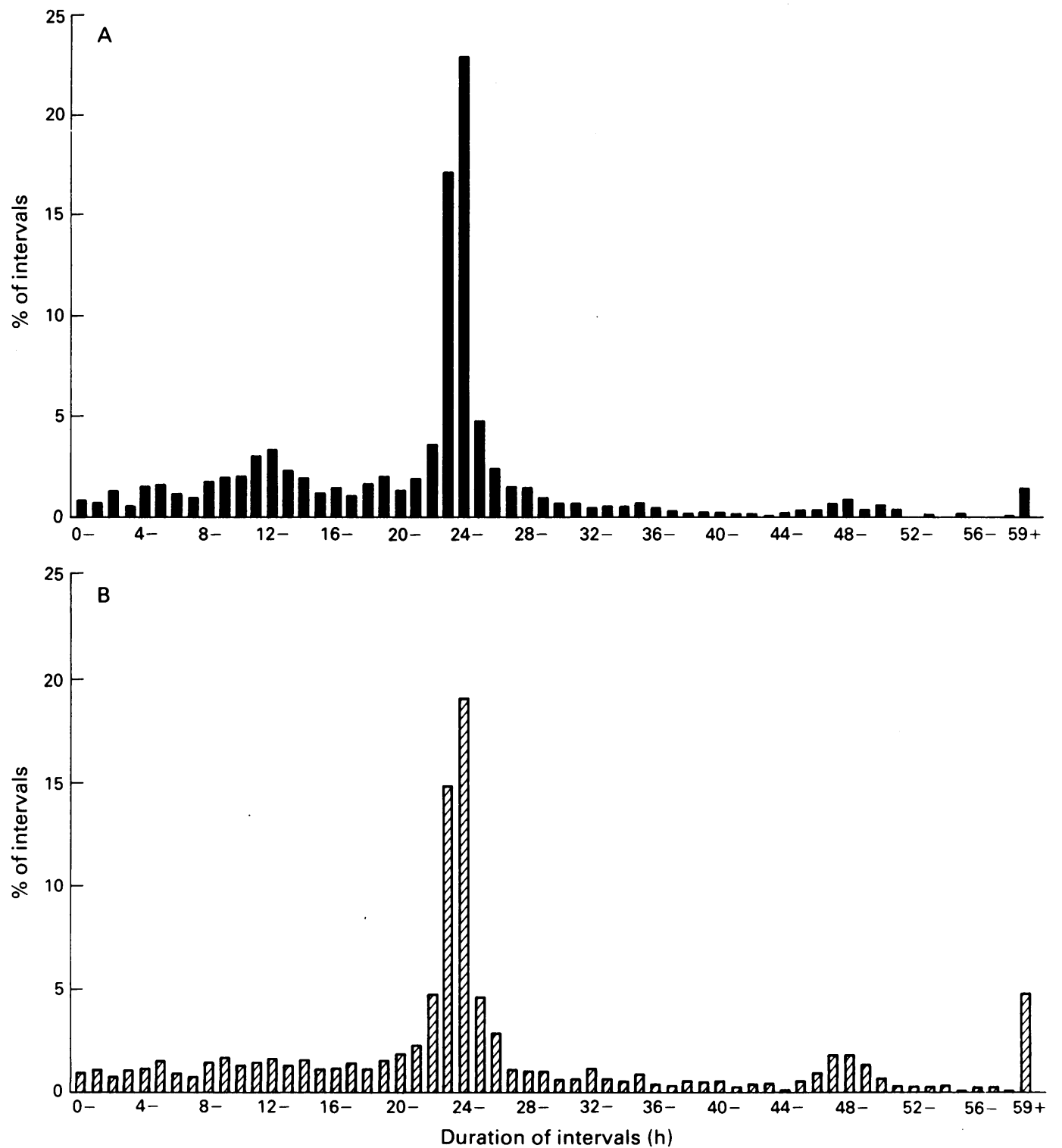

inspection was also more a feature of men $(42 \cdot 0 \%$ $v 36.8 \%$ of women, $\mathrm{p}<0 \cdot 01$ ).

Table IV shows the percentage of men and women claiming each stool type as their usual or most common one. In both sexes stools were most often reported to be sausage or snake like (type 3 or 4 ) and of these most were thought to have a smooth surface (type 4). Stools at the lumpy or constipated end of the spectrum were reportedly commoner in women than men (types 1 and 2 combined 26.5\% v 18.7\%, p<0.001). Loose or breaking up stools (types 5 and 6 ) were reported less often by women of child bearing age than by older women $(7 \cdot 0 \%, v 12.8 \%$, $\mathrm{p}<0.002$ ).

\section{RECORDED DATA}

Forms were returned by $85.6 \%$ of men and $89.8 \%$ of women. Women of $>50$ years were slightly better than younger ones at returning their forms $(93.4 \% v 88.7 \%)$ but the proportion of forms that were able to be analysed was the same in both groups (93.9\%). Eighty six people were excluded because they reported their bowel movements to be atypical. The question on the form about the recorded bowel movements being
Figure 1: Frequency distribution of the intervals between recorded defecations in men of all ages $(A)$ and women of all ages $(B)$. Data obtained from 682 men and 876 women - that is, $61 \cdot 1 \%$ and $58.0 \%$ of the men and women in the original random sample. 
typical was left unanswered by half the subjects but their data were so similar to those of people who said their recordings were typical that the two lots of data were amalgamated.

TIME LAPSE BETWEEN DEFECATIONS

(INTERDEFECATORY INTERVALS)

Many of the intervals between defecations clustered round a peak of 24 hours (Fig 1). This cluster, which seemed to begin at 22 hours and end at 27 hours, included $50.7 \%$ of the intervals in men and $46.2 \%$ in women $(p<0.05)$. It contained fewer intervals in women of child bearing age than in older women $(43.0 \% v$ $58.5 \%, \mathrm{p}<0.001)$. When both a person's intervals were in this cluster - that is, 22-27 hours this was deemed to represent a regular 24 hour cycle. Such regularity was found in more men than women $(40.2 \% v 32.8 \%, \mathrm{p}<0.01)$. It was least common in women of child bearing age $(25.8 \% v 39.3 \%$ in older women $\mathrm{p}<0.001)$.

There were also two smaller clusters of interdefecatory intervals (Fig 1). One was at eight to 15 hours with its peak at 12 hours. It accounted for more of the intervals in men than women $(16 \cdot 1 \% v 10.6 \%, \mathrm{p}<0.001)$. When a person's two intervals added up to about 24 hours - that is, 22-27 hours - this was deemed to represent a regular twice daily bowel habit. Such a habit was apparent in more men than women $(16.5 \% v$ $10.9 \%, p<0.01)$. As a more stringent criterion of a regular twice daily habit we looked for people who had both the kind of record just described and a claimed bowel habit of 14 per week. This criterion was met by rather few people and by more men than women $(6.2 \% v 2.6 \%, \mathrm{p}<0.001)$.

The other cluster of intervals occurred at 4551 hours, peaking at 48 hours. Having both intervals in this range could be taken as evidence of a regular alternate day or 48 hour bowel habit. This was rare, especially in men $(0.4 \% v 2.0 \%$ of women, $\mathrm{p}<0.01$ ).

Intervals longer than 51 hours occurred in only $3.8 \%$ of men but in $10.7 \%$ of women $(\mathrm{p}<0.001)$. Three women recorded an interval of over a week (one did so twice). These women were aged 25,26 , and 32 years.

\section{TIMING OF DEFECATION}

The majority of defecations occurred in the early morning, the peak times being between 0700 and 0800 in men and an hour later in women (Fig 2).
Figure 2: Percentage of defecations in men of all ages (A) and women of all ages (B) which were recorded during each hour of the day and night. Data are grouped into 2460 minute categories starting at midnight. Data obtained from 686 men and 888 women - that is, $61.4 \%$ and $58.8 \%$ of the men and women in the original random sample.
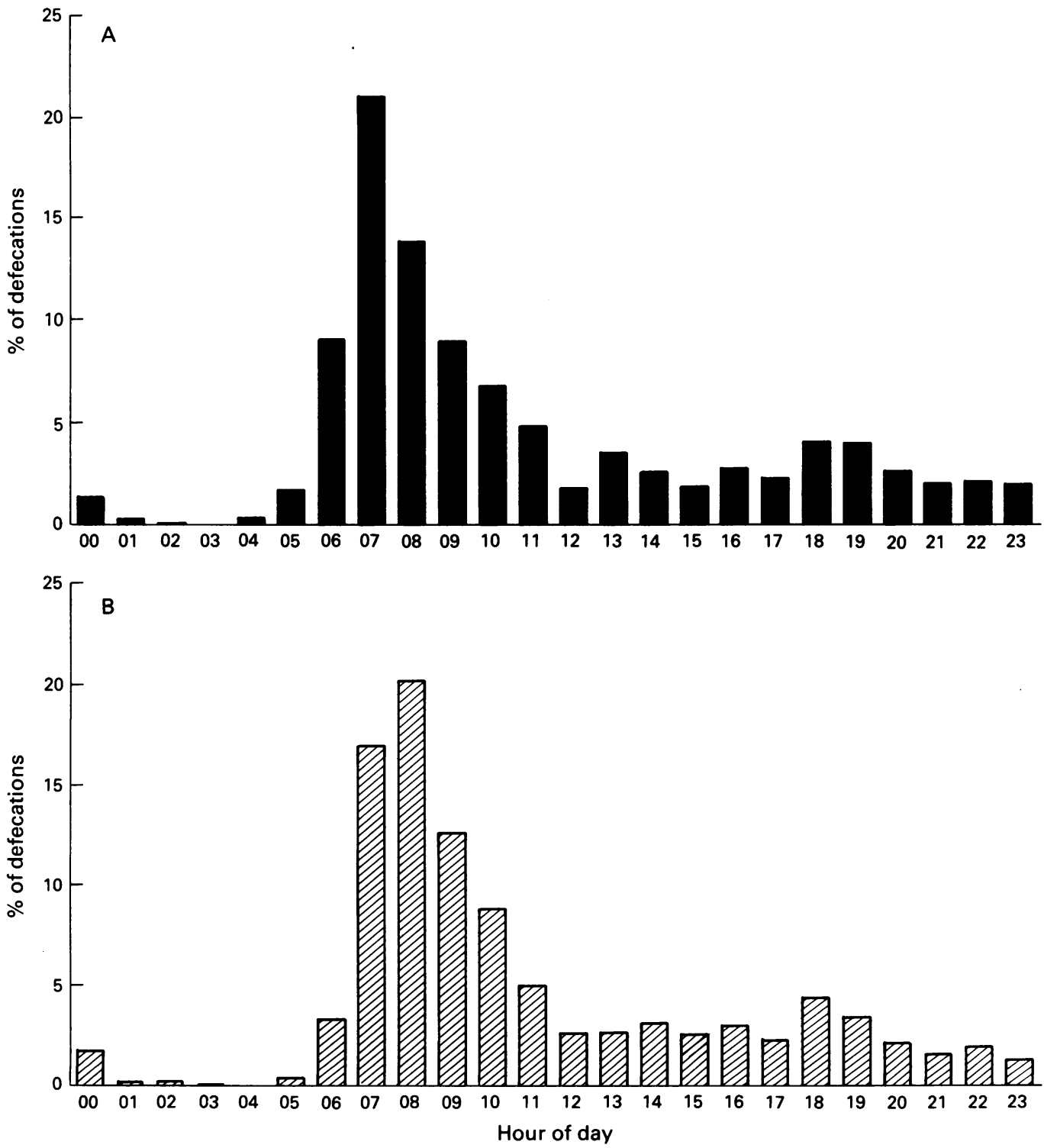
A small second peak occurred in both sexes after 1800 , which is the time when many British people eat their main meal of the day. Very few defecations occurred during the night, especially 0100-0500.

\section{STOOL TYPE}

Table $\mathrm{V}$ shows the percentage of recorded stools in each of the six categories. Type 4 predominated in both sexes (especially men), followed by type 3 and then type 2 . Lumpy stools (types 1 and 2) were more prevalent in women than men of the same age $(25 \cdot 3 \% v 17 \cdot 1 \%)$ whereas mushy stools (type 6) were more common in men $11.9 \% v 8.0 \%$ (both $\mathrm{p}<0.001$ ). Women of child bearing age passed slightly more lumpy stools (types 1 and 2) than older women, namely $26.8 \%$ $v 22.7 \%(\mathrm{p}<0.05)$, and fewer loose or breaking up stools (types 5 and 6), namely $15 \cdot 8 \% v 19 \cdot 3 \%$ $(\mathrm{p}<0.05)$.

\section{RELATIONSHIP OF STOOL TYPE TO PRECEDING TIME} LAPSE

The relationship of stool type to the time lapse since the preceding defecation is shown in Table VI. In both sexes the median time lapse was longest with lumpy stools and shortest with loose stools (types 5 and 6$)(\mathrm{p}<0.001)$ but the differences were very small and the median was always around 24 hours. With every kind of stool except type 6 women had a longer time lapse than men but the differences were mostly trivial.

AGREEMENT BETWEEN REPORTED AND RECORDED INFORMATION

Of the people who claimed to defecate seven

TABLE V Percentage of recorded stools which fell into each of the six types in men and women. The data for women are displayed in such a way as to allow comparison with men of the same age and comparison of childbearing age women with older ones. The subjects available for this analysis comprised $60 \cdot 8 \%$ of the men and $57.9 \%$ of the women in the original random sample

\begin{tabular}{|c|c|c|c|c|}
\hline \multirow[b]{3}{*}{ Stool type } & \multicolumn{4}{|c|}{ Stools in each type (\%) } \\
\hline & \multicolumn{2}{|c|}{ In subjects of 40-69 years } & \multicolumn{2}{|c|}{ In women of 2 ages (years) } \\
\hline & Men & Women & $25-49$ & $50-69$ \\
\hline $\begin{array}{l}1 \\
2 \\
3 \\
4 \\
5 \\
6\end{array}$ & $\begin{array}{r}3 \cdot 75 \\
13 \cdot 35 \\
23 \cdot 23 \\
38 \cdot 58 \\
9 \cdot 16 \\
11.93\end{array}$ & $\begin{array}{r}8.45 \\
16.90 \\
20.52 \\
36.06 \\
10.08 \\
7.99\end{array}$ & $\begin{array}{r}9.93 \\
16.92 \\
23.86 \\
33.49 \\
8.96 \\
6.84\end{array}$ & $\begin{array}{r}7 \cdot 00 \\
15 \cdot 70 \\
20.48 \\
37 \cdot 54 \\
11.26 \\
8.02\end{array}$ \\
\hline
\end{tabular}

TABLE VI Time lapse since the preceding defecation in relation to stool type (median and interquartile range).

Numbers refer to defecations, not people. The per cent of the original random sample providing data is $60.8 \%$ of men and $57 \cdot 9 \%$ of women

\begin{tabular}{|c|c|c|c|}
\hline \multicolumn{2}{|c|}{ Men (all ages) } & \multicolumn{2}{|c|}{ Women (all ages) } \\
\hline Stool typ & Time lapse $(h)$ & Stool type (n) & Time lapse $(h)$ \\
\hline $\begin{array}{l}1(50) \\
2(178) \\
3(313) \\
4(498) \\
5(138) \\
6(175)\end{array}$ & $\begin{array}{l}24 \cdot 0(12 \cdot 9-25 \cdot 6) \\
24 \cdot 0(19 \cdot 7-25 \cdot 5) \\
23 \cdot 8(19 \cdot 3-25 \cdot 2) \\
23 \cdot 8(16 \cdot 0-24 \cdot 5) \\
23 \cdot 3(11 \cdot 8-24 \cdot 1) \\
23 \cdot 5(12 \cdot 0-24 \cdot 3)\end{array}$ & $\begin{array}{l}1(157) \\
2(275) \\
3(410) \\
4(600) \\
5(170) \\
6(132)\end{array}$ & $\begin{array}{l}26 \cdot 0(22 \cdot 8-47 \cdot 3) \\
24 \cdot 1(22 \cdot 0-34 \cdot 8) \\
24 \cdot 1(21 \cdot 0-28 \cdot 3) \\
24 \cdot 0(18 \cdot 5-25 \cdot 2) \\
23 \cdot 6(15 \cdot 4-24 \cdot 5) \\
23 \cdot 0(8 \cdot 3-24 \cdot 1)\end{array}$ \\
\hline
\end{tabular}

times a week $(n=559) 80 \cdot 2 \%$ recorded one or both of their interdefecatory intervals in the appropriate range, that is, $22-27$ hours $(58.0 \%$ both). Agreement was much poorer among the 152 people who claimed a bowel habit of three or four defecations a week - that is, alternate days. Only $34.9 \%$ of them recorded one or both of their intervals in the range $45-51$ hours and a mere $5.9 \%$ had both in this range. The 135 people who claimed a twice daily bowel habit did better, $48.9 \%$ recording two intervals which added up to 22-27 hours.

Concerning stool types, the claimed usual type appeared on the record forms of $72 \cdot 4 \%$ of people and was recorded twice or thrice by $52.9 \%$. Subjects tended to overestimate the constancy of their stool type. Thus, 909 people claimed their stools were generally the same but only $41 \cdot 4 \%$ recorded all three to be the same. Their estimate of the type they passed, however, was quite accurate, $91.0 \%$ recording either the type they had chosen at interview or one next to it on the six point scale.

\section{Discussion}

The main findings of this study are that there are differences between men and women and between women of child bearing age and older women in respect of the frequency and timing of defecation and the form of the stools, all of which suggest that intestinal transit is slower in women especially younger ones. Another major finding is that the conventional norm of a regular once daily bowel habit is actually a minority practice.

The study has limitations. The people chosen for study were not a random sample of the whole United Kingdom or even the whole of Bristol. We believe they were reasonably representative of white city dwellers but the findings are not necessarily applicable to very young women, to young men, or to people in their seventies or older, because we were unable to study them. An appreciable number of invitees did not attend the survey $(27 \cdot 8 \%)$ and if these were atypical the results are skewed. They are unlikely, however, to be atypical as the invitation to the survey did not mention bowel problems. We had to depend on untrained people, the subjects themselves, for all our observations including recording the appearance of their stools - an unpleasant, even repugnant activity. Compliance seemed good, however; nearly $90 \%$ of subjects returned interpretable records. Mistakes may well have been made but in other studies with untrained people selfdetermined stool type correlated with transit time $^{12}$ and was appropriately associated with symptoms of diarrhoea and constipation ${ }^{13}$ so the present data are likely to be valid. Indeed, in a subgroup of the present population, there was a significant correlation between stool form and whole gut transit time and also good reproducibility when a second bowel record form was completed (unpublished data).

The study was not designed to test the reliability of statements about bowel habit but there seemed to be moderately good agreement between reported and recorded information. Eighty per cent of people who claimed a once daily habit showed evidence of such a habit on 
their record forms. Claims of a twice daily habit, however, were borne out only half the time. A 48 hour cycle probably does not occur as a regular habit. People were not very good at predicting the type of their stools and underestimated how much their stools varied in form. This is not surprising as British toilet bowls are so designed, unlike German ones for example, that the stools sink out of sight or nearly so.

The most consistent finding in the study is that women's bowel function is different from that of men. Women defecate less often and, judging from Figure 1, less regularly. The two clusters corresponding with a regular 24 hour cycle and a twice a day cycle account for $66.8 \%$ of defecations in men but only $56.8 \%$ in women. This may reflect the higher proportion of men than women in paid employment and hence having regular hours, but other life style factors and hormonal factors could also be relevant. We also found that women's stool types tend towards the constipated end of the range compared with men's. Others have noted that women report less frequent defecations ${ }^{36711}$ and it is well known that women are the main sufferers from severe constipation..$^{20} 21$ There are also several reports of lower faecal output or slower intestinal transit or both in groups of healthy women compared with men, $122-25$ though not unanimously so. ${ }^{102627}$ Such reports agree with our findings as stool form correlates with transit time. ${ }^{112}$ Our findings of more irregularity and firmer stools in women of child bearing age than older ones agrees with a report that younger women's stools are smaller than those of older women.$^{28}$ It also supports the idea that female sex hormones influence colonic function towards constipation. If more than a week without a bowel action is taken as diagnostic of severe slow transit constipation $^{20}$ then this study suggests that the prevalence of this disorder is about $0.5 \%$ of women aged 25-39 years. We know of no other data on this point.

The lack of any trend to constipation in the oldest age group (60-69 years) may seem surprising in view of the widespread belief that constipation is common in older people. Others, however, have found no clear effect of age on reported bowel habit ${ }^{4}$ and the evidence relating constipation to age ${ }^{62129}$ is based on symptoms of straining and on the prevalence of laxative taking rather than objective measurements. The few physiological measurements that have been done in old people have shown no difference in transit time from young ones ${ }^{30-32}$ and no association between age and 24 hour faecal output. ${ }^{23}$ The present study and the others mentioned, however, did not include very old, frail or house bound people and it may well be that constipation is more prevalent in such people.

Perhaps the most striking finding in this study is the amount of irregular bowel function in the population. Irregularity is likely to be missed in a superficial doorstep enquiry, as used by Everhart et $a l^{6}$ who claimed a once daily habit in $73 \%$ of white Americans. The closer enquiry used by us shows that the conventional norm of a regular 24 hour cycle is in fact a minority practice (39-40\% of men and $31-33 \%$ of women). Other habits which most would accept as normal if they are regular are twice or thrice daily. A twice daily habit was evident in $6 \%$ of men and $3 \%$ of women while $1 \%$ of men and women claimed a thrice daily habit. Between them these three regular habits were present in, at most, $47 \%$ of men and $37 \%$ of women. Therefore, well over half the population had irregular bowel habits. Irregularity was particularly apparent in women of child bearing age, only a quarter of whom produced records compatible with a regular 24 hour cycle.

Similarly, the findings on stool types indicate that conventionally 'normal' stools are not in fact the norm. The stools which best deserve to be called normal are types 3 and 4, especially type 4, because they are the ones associated with least urgency, straining and feelings of incomplete evacuation. ${ }^{13}$ These types comprised only $56 \%$ of the stools passed by women and $61 \%$ of those passed by men. In other words, nearly half the stools passed by this population were suboptimal in terms of comfort.

Most defecations occurred in the early morning, which accords with the general belief that rising and breakfasting are the main cues to opening the bowels. A study in Texan prisoners showed smaller but convincing peaks after lunch and the evening meal. ${ }^{5} \mathrm{We}$ found less evidence of later peaks, perhaps because our subjects did not have their meals at fixed times as prisoners do. The fact that the morning peak was an hour earlier in men may be owing to more Bristol men than women being in employment (and, therefore, rising earlier), to men's bowels responding more briskly to the stimuli of rising and breakfasting, or to women having more distractions (such as children).

There was remarkably little difference between the different stool types in terms of the time lapse before defecation (Table 6). This shows that a bowel history confined to the frequency of defecation is of limited value. A once daily habit is compatible with both fast transit and slow transit and, in an individual, marked changes of colonic function may occur with no change in defecation frequency. Similar findings have been reported in patients with irritable bowel syndrome. ${ }^{12}$

In conclusion, this study has revealed that only a minority of adults enjoy conventionally normal bowel function and little more than half pass normal stools. Younger women are particularly disadvantaged.

Supported by grants from the South West Regional Health Authority and the Kellogg Company of Great Britain.

1 Parks JW. Bowel habit. An investigation based on the examination of 1115 male adults. Cambridge: Cambridge examination of 1115 male adu

2 Hardy TL. Order and disorder in the large intestine. Lancet 1945; i: 519-24

3 Sandler RS, Drossman DA. Bowel habits in apparently healthy young adults not seeking health care. Dig Dis Sci 1987; 32: 841-5.

4 Milne JS, Williamson J. Bowel habit in older people. Geronterol Clin 1972; 14: 56-60.

5 Rendtorff RC, Kashgarian M. Stool patterns of healthy adult males. Dis Colon Rectum 1967; 10: 222-8.

6 Everhart JE, Go VLW, Johannes RS, Fitzsimmons SC, Roth HP, White LR. A longitudinal survey of self-reported bowel habits in the United States. Dig Dis Sci 1989; 34: 1153-62.

7 Connell AM, Hilton C, Irvine G, Lennard-Jones JE, Misiewicz JJ. Variation of bo

8 Manning AP, Wyman JB, Heaton KW. How trustworthy are bowel histories? Comparison of recalled and recorded bowel histories? Comparison of 
9 Chaussade S, Khyari A, Roche H, Garret M, Gaudric M Couturier D, et al. Determination of total and segmental colonic transit time in constipated patients. Results in 9 patients with a new simplified method. Dig Dis Sci 1989; 34 $1168-72$.

10 Wyman JB, Heaton KW, Manning AP, Wicks ACB Variability of colonic function in healthy subjects. Gut 1978 19: $146-50$.

11 Davies GJ, Crowder M, Reid G, Dickerson JWT. Bowe function measurements of individuals with different eating patterns. Gut 1986; 27: 164-9.

12 O'Donnell LJD, Virjee J, Heaton KW. Detection of pseudodiarrhoea by simple clinical assessment of intestinal transit diarrhoea by simple clinical as
rate. $B M 7$ 1990; 300: 439-40.

13 Heaton KW, Ghosh S, Braddon FEM. How bad are the symptoms and bowel dysfunction of patients with the symptoms and bowel dysfunction of patients with the
irritable bowel syndrome? A prospective, controlled study irritable bowel syndrome? A prospective, contro

14 Cleave TL, Campbell GD, Painter NS. Diabetes, coronary thrombosis and the saccharine disease. 2nd ed. Bristol: Wright, 1969.

15 Burkitt DP, Trowell HC, eds. Refined carbohydrate foods and disease. Some implications of dietary fibre. London: Academic Press, 1975.

16 Painter NS. Diverticular disease of the colon. London Heinemann, 1975

17 Petrakis NL, King EB. Cytological abnormalities in nipple aspirates of breast fluid from women with severe constipation. Lancet 1981; ii: 1203-5.

18 Marcus SN, Heaton KW. Intestinal transit, deoxycholic acid and the cholesterol saturation of bile - three inter-related and the cholesterol satura

19 Heaton KW, Braddon FEM, Mountford RA, Hughes AO, Emmett PM. Symptomatic and silent gallstones in the community. Gut 1991; 32: 316-20.

20 Preston DM, Lennard-Jones JE. Severe chronic constipation of young women: 'idiopathic slow transit constipation'. $G u$ $1986 ; 27: 41-8$.
21 Sandler RS, Jordan MC, Shelton BJ. Demographic and dietary determinants of constipation in the US population. Am f Public Health 1990: 80:185-9.

22 Kelsay JL, Clark WM. Fiber intakes, stool frequency, and stool weights of subjects consuming self-selected diets Am F Clin Nutr 1984; 40: 1357-60.

23 Stephen AM, Wiggins HS, Englyst HN, Cole TJ, Wayman BJ, Cummings JH. The effect of age, sex and level of intake of dietary fibre from wheat on large-bowel function in thirty healthy subjects. Br F Nutr 1986;56: 349-61.

24 Metcalf AM, Phillips SF, Zinsmeister AR, MacCarty RI Beart RW, Wolff BG. Simplified assessment of segmental colonic transit. Gastroenterologv 1987; 92: 40-7.

25 Rao SSC, Read NW, Brown C, Bruce C, Holdsworth CD. Studies on the mechanism of bowel disturbance in ulcerative Studies on the mechanism of bowel distur
colitis. Gastroenterologv 1987; $93: 93+40$.

26 Eastwood MA, Brydon WG, Baird JD, Elton RA, Helliwell S Smith JH, et al. Fecal weight and composition, serum lipids, and diet among subjects aged $18-80$ years not seeking health care. Am f Clin Nutr 1984; 40: 628-34

27 Hinds JP, Stoney B, Wald A. Does gender or the menstrual cycle affect colonic transit? Am $\mathcal{F}$ Gastroenterol 1989;84 $123-6$

28 Brauer PM, Slavin JL, Marlett JA. Apparent digestibility of neutral detergent fiber in elderly and young adults. Am F Clin Nutr 1981; 34: 1061-70.

29 Thompson WG, Heaton KW. Functional bowel disorders in apparently healthy people. Gastroenterologv 1980; 79: 283-8.

30 Eastwood HDH. Bowel transit studies in the elderly: radioopaque markers in the investigation of constipation. opaque markers in the inve
Geronterol Clin 1972;14:15t-9.

31 Gear JSS, Brodribb AJM, Ware A, Mann JI. Fibre and bowe transit times. BrF Nutr 1981; 45: 77-82

32 van der Werf SDJ, Huijbregts AWM, Lamers HLM, van Berge Henegouwen GP, van Tongeren JHM. Age dependent differences in human bile acid metabolism and $7 u$ dehydroxylation. Eur $\mathcal{F}$ Clin Invest 1981; 11: +25-31. 